\title{
The function and mechanism of HMGB1 in lung cancer and its potential therapeutic implications (Review)
}

\author{
LEI WU ${ }^{1-3}$ and LILI YANG ${ }^{1-3}$ \\ ${ }^{1}$ Department of Immunology, Tianjin Cancer Institute and Hospital, Tianjin Medical University; \\ ${ }^{2}$ National Clinical Research Center of Cancer; ${ }^{3}$ Key Laboratory of Cancer Immunology and Biotherapy, \\ Tianjin Cancer Institute and Hospital, Tianjin Medical University, Tianjin 300060, P.R. China
}

Received February 22, 2017; Accepted January 22, 2018

DOI: $10.3892 / \mathrm{ol} .2018 .8215$

\begin{abstract}
As a non-histone chromatin-associated protein, high-mobility group box-1 (HMGB1) performs a pivotal function in various human diseases, including autoimmune diseases, neurodegenerative diseases and cancer. Overexpression of HMGB1 has been demonstrated in numerous types of cancer, including breast cancer, colorectal cancer, lung cancer and hepatocellular carcinoma. However, the underlying mechanism of HMGB1 function in lung cancer remains to be elucidated. The present study aimed to analyze, and summarize the role and mechanism of HMGB1 in lung cancer by retrieving available literature regarding HMGB1 in association with lung cancer. It provides comprehensive information on the association of HMGB1 with the carcinogenesis and progression of lung cancer, and discusses the molecular mechanism of these processes. HMGB1 may induce tumorigenesis, metastasis and chemotherapy resistance in lung cancer. Overall, it is evident that HMGB1 serves an important role in the development and progression of lung cancer, and this review warrants further investigation into HMGB1 as a novel target for cancer therapy.
\end{abstract}

\section{Contents}

1. Introduction

2. Receptors and regulation

3. Role of HMGB1 in lung cancer

4. HMGB1-targeting therapeutic strategies

5. Conclusions and perspectives

Correspondence to: Dr Lili Yang, Department of Immunology, Tianjin Cancer Institute and Hospital, Tianjin Medical University, Huanhuxi Road, Tiyuanbei, Hexi, Tianjin 300060, P.R. China

E-mail: yanglili@tjmuch.com

Key words: high-mobility group protein B1, lung cancer, proliferation, function

\section{Introduction}

Lung cancer has a high prevalence worldwide, and is associated with the highest morbidity and mortality rates among all types of malignant tumor (1). Small cell lung carcinoma (SCLC) and non-small cell lung carcinoma (NSCLC), develop and metastasize differently, and are the two groups of lung cancer (2). Lung cancer tumors are commonly treated through surgery, chemotherapy, radiation therapy or targeted drug therapy. However, lung cancer is usually detected at the advanced stage, and, in severe cases, cancer cells may have already metastasized to other organs (3). Therefore, the identification of biomarkers to allow for early detection, diagnosis and therapeutic targeting of lung cancer is required.

High-mobility group box 1 (HMGB1), a member of the high-mobility group protein superfamily, is widely expressed and highly abundant $(4,5)$. HMGB1 is secretively and intracellularly active, and serves important roles in biological and pathological processes $(4,6,7)$. HMGB1 exists in the nucleus, and acts as an architectural chromatin-binding factor by binding DNA, thus maintaining the structure and stability of chromosomes (8). HMGB1 also translocates to the cytoplasm, where it activates autophagy by binding to beclin1 (9). Secretive HMGB1 is actively secreted by immune cells, and passively released during cell death and cell injury $(8,10,11)$. It serves as an extracellular signaling molecule and damage-associated molecular pattern molecule (12). Once released, soluble HMGB1 binds to several cell surface receptors, including receptor for advanced glycation end-products (RAGE) (13) and toll-like receptors (TLRs) $(14,15)$, to initiate functional responses by activating downstream signaling pathways. This results in the activation of immune cell activities, the induction of proinflammatory cytokines, stimulation of cell adhesion and migration, promotion of cell proliferation and angiogenesis, and induction of autophagy (16-18).

Although it has been previously suggested that upregulated expression of HMGB1 is associated with lung cancer, the underlying mechanisms of lung cancer oncogenesis and progression remain to be fully elucidated. The present study aimed to summarize the effects of HMGB1 on the oncogenesis and progression of lung cancer, and to reveal the hallmarks and potential therapeutic targets of this mechanism. 


\section{Receptors and regulation}

HMGB1 serves an important role in the generation and development of lung cancer (19). The role of HMGB1 in mediating carcinogenesis and metastasis of lung cancer has been previously investigated. HMGB1 is associated with RAGE and TLRs via three primary pathways, including phosphoinositide-3-kinase (PI3K)/RAC- $\alpha$ serine/threonineprotein kinase (Akt), nuclear factor- $\mathrm{\kappa B}[\mathrm{NF}-\kappa \mathrm{B}$ (P56)], and mitogen activated protein kinase (MAPK) [extracellular signal-regulated kinase 1/2 (ERK1/2), p38)].

$R A G E$. This protein belongs to the immunoglobulin superfamily of transmembrane proteins, and is shared by numerous ligands, including HMGB1 and amphoterin $(20,21)$. The co-expression of HMGB1 and RAGE is associated with the invasive and metastatic potential of hepatocellular carcinoma (22-24). In normal human bronchial epithelial cells, the HMGB1-induced inflammatory response promotes the activities of the RAGE/c-Jun N-terminal kinase 1 (JNK)/NF- $\kappa B$ pathway by binding to RAGE $(25,26)$. The pro-inflammatory activity of HMGB1 is associated with the pathogenesis of precancerous lesions $(27,28)$. RAGE also interacts with amphoterin, which contributes to tumor growth and metastasis (29). Compound NBRI17671 (2) is a RAGE inhibitor that downregulates MAPK activity and effectively inhibits the growth of lung tumor xenografts in mice (30). This phenomenon maybe attributed to the blockade of RAGE-amphoterin. Notably, RAGE is highly expressed in normal tissues, particularly in the lungs (31). However, the expression level of RAGE in the serum and tissue of patients with lung cancer is lower compared with that of normal lung tissue (32-34).

HMGB1 promotes cancer cell migration and invasion, as well as angiogenesis, growth and metastasis of cancer by regulating matrix metallopeptidase 9 (MMP-9) in lung cancer $(28,29)$. HMGB1 expression is positively associated with MMP-9 expression (35). The potential mechanism involves the formation of a HMGB1-RAGE complex, which activates MAPK signaling pathways and MMP-9. Following MMP-9 activation, the extracellular matrix is degraded, allowing tumor invasion and metastasis to occur $(36,37)$. HMGB1-induced MMP-9 expression has been reported to be associated with tumor metastasis in NSCLC. The overexpression of HMGB1 activates MMP-9 by triggering the PI3K/Akt and NF- $\mathrm{KB}$ signaling pathways (38).

$T L R s$. These pattern recognition receptors activate a cascade of downstream signals, resulting in the secretion of inflammatory cytokines, chemokines and type I interferons $(39,40)$. TLRs are evolutionary conserved from invertebrates to humans, and the TLR family has $\geq 13$ members (41). TLR2, 4 and 9 have been identified as receptors of HMGB1 (42). TLRs have also recently emerged as key immunomodulators of the immune response in carcinogenesis and tumor progression (43).

TLR2 is an inflammation-associated receptor, expressed on megakaryocytes and platelets (44). It has been implicated in inflammation-induced platelet activation and vascular diseases (45). Elevated expression of TLR2 and its functional activation are exhibited by monocytes of patients with type 2 diabetes mellitus, suggesting a molecular association between inflammation and diabetes (46). A previous study demonstrated HMGB1 to be a ligand, which endogenously activates TLR2 in several pathological conditions (47). HMGB1 is released during exposure to acute hypoxia and activates TLR2 (48). Activated TLR2, in turn, induces the upregulation and secretion of von Wille brand factor, thus promoting insulin resistance (48). Another study demonstrated that HMGB1 upregulates the expression of TLRs in natural killer (NK) cells and promotes the maturation of NK cells in ageing mice. The activation of NK cells lead to an increased and persistent immune response in cholangiocytes, inducing biliary atresia (49). In human and mouse breast cancer stem cells (CSCs), the HMGB1/TLR2 axis promotes NF- $\mathrm{KB}$ activation, interleukin- 6 and transforming growth factor $\beta$ production, as well as signal transducer and activator of transcription 3, and SMAD family member 3 activation. These cytokines are known to affect CSC self-renewal and tumor-generating ability (50).

TLR4 is a receptor of HMGB1, and NF- $\kappa \mathrm{B}$ and MAPK expression levels are increased when TLR4 is activated by HMGB1 $(51,52)$. NF- $\kappa B$ and MAPKs regulate the expression of inflammatory genes, and participate in the proliferation, invasion and metastasis of tumor cells (52). One study demonstrated that the interaction between TLR4 on platelets and tumor-cell HMGB1 promotes the metastasis of Lewis lung carcinoma (LLC) tumor cells in vitro and in vivo (53). Therefore, TLR4 mayact as a therapeutic target to prevent platelet-mediated tumor metastasis.

HMGB1 was reported to be involved in the regulation of cell autophagy at the transcriptional level (54). Reciprocally, it has been suggested that autophagy regulates the induction of HMGB1 secretion (55). Following its upregulation, HMGB1 translocates from the nucleus to the cytoplasm in Lewis cells upon nutrient depletion. The starvation of Lewis cells promotes HMGB1 secretion, which induces autophagy and inhibits apoptosis by activating a RAGE-HMGB1/ERK1/2-dependent pathway (56). This indicates that HMGB1 overexpression may serve as a Lewis lung carcinoma risk factor, stimulating cancer growth and metastasis. Another study reported that HMGB1 significantly stimulates the proliferation of Lewis cells and inhibits apoptosis in vitro via the HMGB1-RAGE/TLR4-PI3K/Akt or HMGB1-RAGE/TLR4-ERK1/2 pathways (55). Thus, there is conflicting evidence regarding the contribution of HMGB1 to apoptosis and proliferation. However, these findings provide a basis for future investigations.

TLR9 is localized in the endoplasmic reticulum, but redistributes to early endosomes upon activation by CpG-DNA or synthetic CpGoligodeoxynucleotide (ODN) analogs $(57,58)$. HMGB1 acts as a CpG-ODN-binding protein. CpG-ODN stimulates macrophages and dendritic cells to secrete HMGB1. HMGB1 enhances the immunostimulatory potential CpG-ODNs in a TLR9-dependent manner (54). Activated TLR9 recruits Myeloid differentiation primary response protein MyD88 (MyD88), allowing the execution of subsequent immune responses (59). The interaction between TLR9 and $\mathrm{CpG}$ ODN promotes 95D cell proliferation in vitro, and in vivo $(36,60)$. On the basis of these studies, Wang et al (37) indicated that extracellular HMGB1 contributes to the proliferation of lung cancer 95D cells via MyD88-dependent RAGE 
and TLR4 signaling. Sun et al (61) also reported that HMGB1 functions in the regulation of ERK1/2 and p38 MAPK signaling pathways, which are implicated in the proliferation, and invasion of lung cancer cells. P38 and ERK1/2, activated by HMGB1, transcriptionally regulate NF- $\mathrm{kB}$, resulting in cell proliferation and lung cancer development (61).

\section{Role of HMGB1 in lung cancer}

$H M G B 1$ expression in patients with lung cancer. HMGB1 has been associated with the prognosis of patients with lung. The expression levels of HMGB1 in the tissue and serum of patients with lung cancer are significantly higher compared those of normal lung tissue samples $(62,63)$. HMGB1 levels are positively associated with tumor size, tumor node metastasis stage and distant metastasis (42). In patients with NSCLC, the serum level of HMGB1 detected one month subsequent to surgery was significantly increased compared with the pre-operative level (43). An increased level of HMGB1 in the serum of patients with progressive NSCLC was associated with shorter overall survival and disease-free survival times (64). Therefore, HMGB1 may be considered as a potential biomarker for the diagnosis and prognosis of patients with NSCLC $(45,46)$. There is varying evidence regarding the average expression level of HMGB1, due to heterogeneity of detection methods, small sample sizes and low statistical power (42). Thus, whether HMGB1 is over- or underexpressed in patients with lung cancer remains unclear, and requires confirmation and clinical validation (19).

HMGB1 and tumorigenesis. As HMGB1 expression has been demonstrated to be increased in lung cancer tissue, serum and cell lines, researchers have suggested that the overexpression of HMGB1 contributes to the development, and progression of lung cancer (61). The underlying molecular mechanisms regarding the contribution of HMGB1 to the progression of lung cancer have been investigated. It was indicated that HMGB1 enhances the growth of 95D cells through acting synergistically with CpG-ODN (37). Another study reported that HMGB1 exerts its effects by regulating ERK1/2 and p38 MAPK signaling pathways, which are both implicated in cell proliferation, and lung cancer development (61).

Cytoplasmic HMGB1 binds beclin $1(65,66)$, and p53 is a negative regulator of the HMGB1/beclin 1 complex. The exogenous HMGB1 promotes autophagy in tumor cells through interactions with RAGE $(67,68)$. HMGB1 binds to 553 to regulate the cytoplasmic localization of the HMG1/beclin 1 complex (69). The HMGB1/p53 complex also regulates the balance between tumor cell death and survival (70). A previous study reported that p53-knockout in human colorectal cancer cells increased the expression of cytosolic HMGB1 and upregulated autophagy (70). However, to the best of our knowledge, the role of the HMGB1/p53 complex in lung cancer has not been previously reported.

HMGB1 and metastasis. Metastasis is a hallmark of malignant tumors, and the principal cause of mortality in patients with lung cancer (41). NF-kB p65 was initially identified in mature immune cells and was reported to regulate cellular functions through various signaling pathways (71). p65 is positively associated with metastasis (62). Zhang et al (71) observed that p65 expression in patients with NSCLC was remarkably higher compared with that in healthy patients. Furthermore, the protein expression levels of HMGB1 and p65 were significantly higher in patients exhibiting lymph node metastasis compared with patients without metastasis. Correlation analysis revealed that HMGB1 and p65 protein expression levels are positively correlated with NSCLC metastasis (71).

MicroRNAs (miRNAs) inhibit cancer cell migration and invasion through the suppression of HMGB1 (66-68). miRNAs affect mRNA cleavage or translational repression by directly targeting the 3'-untranslated region of HMGB1 mRNA (66). Zhang et al (72) observed that miR-218 overexpression negatively regulated HMGB1 expression at the mRNA and protein levels, and further inhibited cell migration and invasion in human lung cancer cell lines, A549 and H1299. The expression of miR-325-3p was demonstrated to be negatively correlated with that of HMGB1 in human lung cancer tissues (73). Patients with NSCLC exhibiting low miR-325-3p expression had significantly shorter overall and progression-free survival times compared with patients exhibiting high miR-325-3p expression. These results indicate that the overexpression of miR-325-3p may indicate good prognosis, and act as a potential prognostic and predictive marker for patients with NSCLC (73). Further investigation demonstrated that miR-142-3p may modulate cell tumorigenesis by targeting HMGB1 in NSCLC (74). Another study indicated that miR-181b directly targeted HMGB1 in NSCLC cells and that miR-181b has been demonstrated to inhibit NSCLC cell motility (75). These results suggest that miR-142-3p and miR-181b may be novel therapeutic agents to prevent NSCLC from becoming invasive (74,75). Zhu et al (76) reported that HMGB1 enhances the metastatic ability of NSCLC cells by activating $\alpha v \beta 3 /$ focal adhesion kinase through the TLR4/NF- $\mathrm{KB}$ signaling pathway.

HMGB1 and chemotherapy resistance. In various treatment regimens for lung cancer, chemotherapy is often the first line of treatment for patients with lung cancer, particularly NSCLC (77,78), and cisplatin (DDP) and carboplatin are commonly used drugs. However, several survival mechanisms, including anti-apoptosis, drug resistance and immune defense, compromise the therapeutic efficacy of these drugs (79-81). HMGB1 is highly expressed in NSCLC cell lines. The levels of HMGB1 in NSCLC cells treated with chemotherapeutics were increased compared with untreated cells. The expression of autophagy-associated proteins beclin 1 and LC3-II were significantly higher in DDP-resistant cells compared with A549 cells treated with chemotherapeutic drugs (7). These data suggest that HMGB1 expression is associated with drug resistance. HMGB1-induced cell autophagy inhibited cell apoptosis in DDP-resistant lung cancer cells (7). Another mechanistic investigation revealed that HMGB1 inhibited apoptosis and increased drug resistance through activating the MAPK-ERK signaling pathway, thereby promoting the formation of the beclin-1-PI3K-III complex (82).

The function of HMGB1-associated proteins in chemotherapy-induced DNA damage has been assessed in human carcinoma A549 cells by gene knockdown using short interfering RNAs (83). This revealed that the chemosensitivity of A549 cells to cytarabine was decreased by $8-50$ fold, and that 


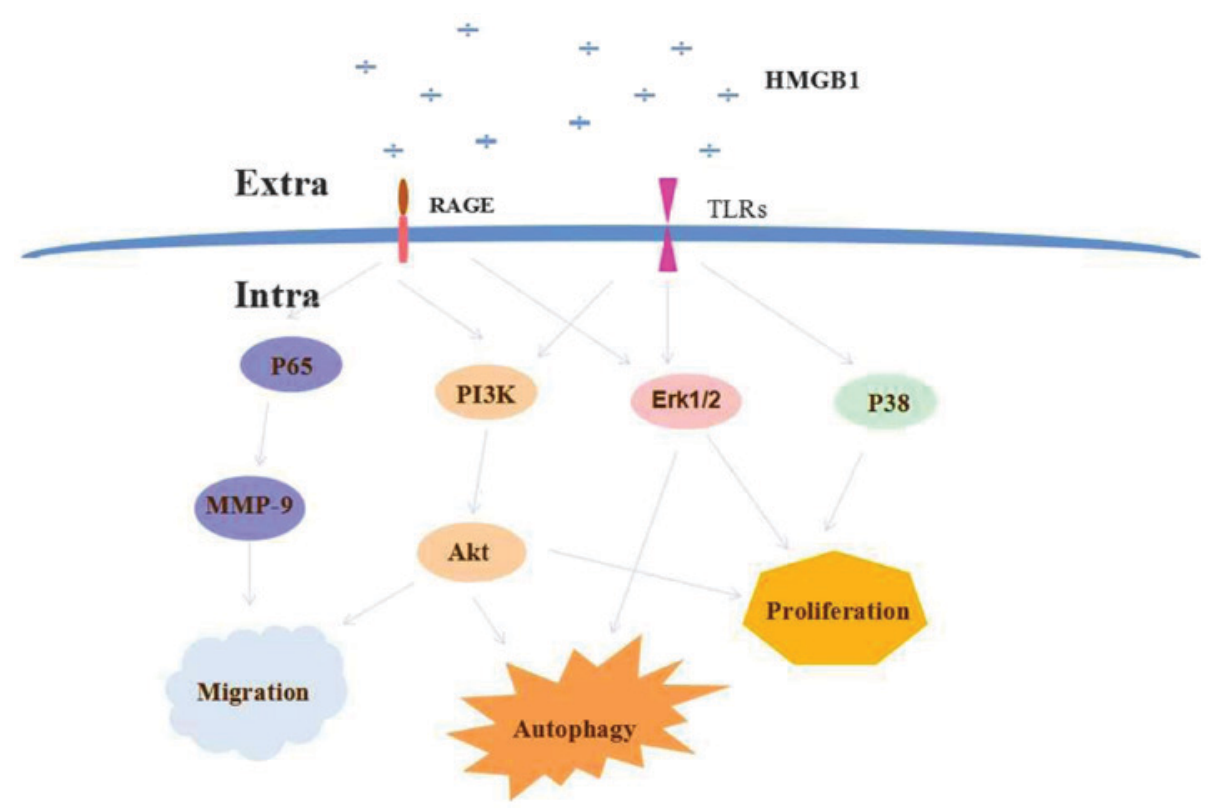

Figure 1. HMGB1 modulates cell proliferation, cell death and metastasis. The overexpression of HMGB1 induces the activation of PI3K/Akt, NF- $\kappa B$ (p56) and MAPK (ERK1/2, p38) signaling pathways by binding to RAGE or TLRs on lung cancer cells. HMGB1, high-mobility group protein B1; PI3K, phosphoinositide-3-kinase; NF- $\mathrm{B}$, nuclear factor-кB; MAPK, mitogen activated protein kinase; ERK, extracellular signal-regulated kinase 1/2; RAGE, receptor for advanced glycation end-products; TLR, toll-like receptor; MMP9, matrix metallopeptidase 9; extra, extracellular; intra, intracellular.

HMGB1 and HMGB2 participate in this process by modulating p53 phosphorylation (83). These results improve the existing understanding of the mechanism of chemotherapy resistance. Aranda et al (84) demonstrated that pyridoxine, a precursor of vitamin B6, increases the immunogenicity of cisplatin-induced cell death in patients with NSCLC. This may have important implications for the development of novel strategies to circumvent cis-diamminedichloroplatinum (II) resistance.

\section{HMGB1-targeting therapeutic strategies}

Lung cancer may be treated by inhibiting HMGB1 production. Although research on this rationale has been conducted in vitro and in vivo, clinical studies are yet to be performed. Therefore, direct evidence of the potential efficacy of therapeutic strategies targeting HMGB1 in lung cancer is not yet available (85).

Sodium salicylate. Sodium salicylate, which is the active metabolite of aspirin, elicits anti-inflammatory activity by inhibiting the expression or activation of various pro-inflammatory factors, including cyclooxygenase 2 , inducible nitric oxide synthase and interleukin-1 $\beta$ (85). Sodium salicylate is also involved in defense against tumor development and progression (86). Sodium salicylate may potentially suppress the release of HMGB1 from necrotic cells by redirecting glucose deprivation-induced necrosis to autophagy; as a result, inflammatory responses and tumor development are prevented (87). Therefore, sodium salicylate may be used as a novel agent for the control and treatment of lung cancer.

Ethyl pyruvate (EP). EP inhibits the levels of HMGB1 secreted from endotoxin-stimulated macrophages (88). EP has been applied to HMGB1-associated therapeutic strategies for hepatocellular carcinoma in animal models (89). EP reportedly induces the death of lung adenocarcinoma A549 cells (88). The underlying mechanism of EP is similar to that of sodium salicylate. Guo et al (90) suggested that EP significantly inhibits the development of murine colitis by inhibiting HMGB1-T-helper 17 (Th17) and Th1/transcriptional and immune response regulator responses. These results may provide a novel perspective on the interaction between EP and HMGB1.

\section{Conclusions and perspectives}

In summary, HMGB1 overexpression is involved in various diseases, including lung cancer.HMGB1 has been demonstrated to induce tumorigenesis, metastasis and chemotherapeutic responses in lung cancer. HMGB1 receptors involved in lung cancer progression include RAGE and TLRs. The effects of HMGB1 are executed via various signaling pathways, including PI3K/Akt, NF- $\mathrm{B}$ (p65) and MAPK (ERK1/2, p38). A schematic illustration of HMGB1 signaling in lung cancer is presented in Fig. 1.

The present study summarizes the association between HMGB1 with the oncogenesis and progression of lung cancer. It not only elucidates the molecular mechanism of carcinogenesis and progression of lung cancer, but also provides a reliable basis for further investigation. HMGB1 may be a potential treatment target for early disease diagnosis. It may have potential in therapeutic research for lung cancer, and thus required further investigation.

\section{Acknowledgements}

Not applicable.

\section{Funding}

The present study was supported by the National Key Technology R\&D Program (grant no. 2015BAI12B12), Key 
Projects of Tianjin Health Industry (grant no. 15KG145) and the National Natural Science Foundation of China (grant no. 81572265 and 31500736 ).

\section{Availability of data and materials}

Not applicable.

\section{Authors' contributions}

LY participated in the conception and design of this work. LW searched the literature, and drafted and revised the manuscript. All authors have read and approved the manuscript.

\section{Ethics approval and consent to participate}

Not applicable.

\section{Consent for publication}

Not applicable.

\section{Competing interests}

The authors declare that they have no competing interests.

\section{References}

1. Sánchez de Cos J, Sojo González MA, Montero MV, Pérez Calvo MC, Vicente MJ and Valle MH: Non-small cell lung cancer and silent brain metastasis. Survival and prognostic factors. Lung Cancer 63: 140-145, 2009.

2. Wood SL, Pernemalm M, Crosbie PA and Whetton AD: Molecular histology of lung cancer: From targets to treatments. Cancer Treat Rev 41: 361-375, 2015.

3. Khan $\mathrm{N}$ and Mukhtar H: Dietary agents for prevention and treatment of lung cancer. Cancer Lett 359: 155-164, 2015.

4. Shang GH, Jia CQ, Tian H, Xiao W, Li Y, Wang AH, Dong L and Lin DJ: Serum high mobility group box protein 1 as a clinical marker for non-small cell lung cancer. Respir Med 103: 1949-1953, 2009.

5. Andersson U, Antoine DJ and Tracey KJ: The functions of HMGB1 depend on molecular localization and post-translational modifications. J Intern Med 276: 420-424, 2014.

6. Sun X and Tang D: HMGB1-dependent and -independent autophagy. Autophagy 10: 1873-1876, 2014.

7. Zhang R, Li Y, Wang Z, Chen L, Dong X and Nie X: Interference with HMGB1 increases the sensitivity to chemotherapy drugs by inhibiting HMGB1-mediated cell autophagy and inducing cell apoptosis. Tumour Biol 36: 8585-8592, 2015.

8. Yu Y, Tang D and Kang R: Oxidative stress-mediated HMGB1 biology. Front Physiol 6: 93, 2015.

9. Kang R, Livesey KM, Zeh HJ, Loze MT and Tang D: HMGB1: A novel beclin 1-binding protein active in autophagy. Autophagy 6 : 1209-1211, 2010

10. Goh WW, Fan M, Low HS, Sergot M and Wong L: Enhancing the utility of proteomics signature profiling (PSP) with pathway derived subnets (PDSs), performance analysis and specialised ontologies. BMC Genomics 14: 35, 2013.

11. Musumeci D, Roviello GN and Montesarchio D: An overview on HMGB1 inhibitors as potential therapeutic agents in HMGB1-related pathologies. Pharmacol Ther 141: 347-357, 2014.

12. Bianchi ME: HMGB1 loves company. J Leukoc Biol 86: 573-576, 2009.

13. Hori O, Brett J, Slattery T, Cao R, Zhang J, Chen JX, Nagashima M, Lundh ER, Vijay S, Nitecki D, et al: The receptor for advanced glycation end products (RAGE) is a cellular binding site for amphoterin. Mediation of neurite outgrowth and co-expression of rage and amphoterin in the developing nervous system. J Biol Chem 270: 25752-25761, 1995.
14. Park JS, Svetkauskaite D, He Q, Kim JY, Strassheim D, Ishizaka A and Abraham E: Involvement of toll-like receptors 2 and 4 in cellular activation by high mobility group box 1 protein. J Biol Chem 279: 7370-7377, 2004.

15. Tian J, Avalos AM, Mao SY, Chen B, Senthil K, Wu H, Parroche P, Drabic S, Golenbock D, Sirois C, et al: Toll-like receptor 9-dependent activation by DNA-containing immune complexes is mediated by HMGB1 and RAGE. Nat Immunol 8: 487-496, 2007.

16. Tang D, Kang R, Coyne CB, Zeh HJ and Lotze MT: PAMPs and DAMPs: Signal 0s that spur autophagy and immunity. Immunol Rev 249: 158-175, 2012.

17. Park JS, Gamboni-Robertson F, He Q, Svetkauskaite D, Kim JY, Strassheim D, Sohn JW, Yamada S, Maruyama I, Banerjee A, et al: High mobility group box 1 protein interacts with multiple Toll-like receptors. Am J Physiol Cell Physiol 290: C917-C924, 2006.

18. Lee SA, Kwak MS, Kim S and Shin JS: The role of high mobility group box 1 in innate immunity. Yonsei Med J 55: 1165-1176, 2014.

19. Shen X, Hong L, Sun H, Shi M and Song Y: The expression of high-mobility group protein box 1 correlates with the progression of non-small cell lung cancer. Oncol Rep 22: 535-539, 2009.

20. Rouhiainen A, Kuja-Panula J, Tumova S and Rauvala H: RAGE-mediated cell signaling. Methods Mol Biol 963: 239-263, 2013.

21. Sirois CM, Jin T, Miller AL, Bertheloot D, Nakamura H, Horvath GL, Mian A, Jiang J, Schrum J, Bossaller L, et al: RAGE is a nucleic acid receptor that promotes inflammatory responses to DNA. J Exp Med 210: 2447-2463, 2013.

22. Chen RC, Yi PP, Zhou RR, Xiao MF, Huang ZB, Tang DL, Huang Y and Fan XG: The role of HMGB1-RAGE axis in migration and invasion of hepatocellular carcinoma cell lines. Mol Cell Biochem 390: 271-280, 2014.

23. Riuzzi F, Sorci G and Donato R: The amphoterin (HMGB1)/ receptor for advanced glycation end products (RAGE) pair modulates myoblast proliferation, apoptosis, adhesiveness, migration, and invasiveness. Functional inactivation of RAGE in L6 myoblasts results in tumor formation in vivo. J Biol Chem 281: 8242-8253, 2006.

24. Yaser AM, Huang Y, Zhou RR, Hu GS, Xiao MF, Huang ZB, Duan CJ, Tian W, Tang DL and Fan XG: The Role of receptor for advanced glycation end products (RAGE) in the proliferation of hepatocellular carcinoma. Int J Mol Sci 13: 5982-5997, 2012.

25. Wu X, Mi Y, Yang H, Hu A, Zhang Q and Shang C: The activation of HMGB1 as a progression factor on inflammation response in normal human bronchial epithelial cells through RAGE/JNK/NF- $\mathrm{KB}$ pathway. Mol Cell Biochem 380: 249-257, 2013.

26. Liang Y, Hou C, Kong J, Wen H, Zheng X, Wu L, Huang H and Chen Y: HMGB1 binding to receptor for advanced glycation end products enhances inflammatory responses of human bronchial epithelial cells by activating p38 MAPK and ERK1/2. Mol Cell Biochem 405: 63-71, 2015.

27. Ohmori H, Luo $\mathrm{Y}$ and Kuniyasu $\mathrm{H}$ : Non-histone nuclear factor HMGB1 as a therapeutic target in colorectal cancer. Expert Opin Ther Targets 15: 183-193, 2011.

28. Nogueira-Machado JA and de Oliveira Volpe CM: HMGB-1 as a target for inflammation controlling. Recent Pat Endocr Metab Immune Drug Discov 6: 201-209, 2012.

29. Taguchi A, Blood DC, del Toro G, Canet A, Lee DC, Qu W, Tanji N, Lu Y,Lalla E, Fu C, et al: Blockade of RAGE-amphoterin signalling suppresses tumour growth and metastases. Nature 405: 354-360, 2000

30. Kawada M, Usami I, Someno T, Watanabe T, Abe H, Inoue H, Ohba S, Masuda T, Tabata Y, Yamaguchi S and Ikeda D: NBRI17671, a new antitumor compound, produced by Acremonium sp. CR17671. J Antibiot (Tokyo) 63: 237-243, 2010.

31. Brett J, Schmidt AM, Yan SD, Zou YS, Weidman E, Pinsky D, Nowygrod R, Neeper M, Przysiecki C, Shaw A, et al: Survey of the distribution of a newly characterized receptor for advanced glycation end products in tissues. Am J Pathol 143: 1699-1712, 1993.

32. Schraml P, Bendik I and Ludwig CU: Differential messenger RNA and protein expression of the receptor for advanced glycosylated end products in normal lung and non-small cell lung carcinoma. Cancer Res 57: 3669-3671, 1997.

33. Katsuoka F, Kawakami Y, Arai T, Imuta H, Fujiwara M, Kanma H and Yamashita K: Type II alveolar epithelial cells in lung express receptor for advanced glycation end products (RAGE) gene. Biochem Biophys Res Commun 238: 512-516, 1997. 
34. Wang H, Li Y, Yu W, Ma L, Ji X and Xiao W: Expression of the receptor for advanced glycation end-products and frequency of polymorphism in lung cancer. Oncol Lett 10: 51-60, 2015.

35. Wang JL, Wu DW, Cheng ZZ, Han WZ, Xu SW and Sun NN: Expression of high mobility group box-B1 (HMGB-1) and matrix metalloproteinase-9 (MMP-9) in non-small cell lung cancer (NSCLC). Asian Pac J Cancer Prev 15: 4865-4869, 2014.

36. Xu L, Zhou Y, Liu Q, Luo JM, Qing M, Tang XY, Yao XS, Wang $\mathrm{CH}$ and Wen $\mathrm{ZK}$ : CXCR4/SDF-1 pathway is crucial for TLR9 agonist enhanced metastasis of human lung cancer cell. Biochem Biophys Res Commun 382: 571-576, 2009.

37. Wang C, Fei G, Liu Z, Li Q, Xu Z and Ren T: HMGB1 was a pivotal synergistic effecor for $\mathrm{CpG}$ oligonucleotide to enhance the progression of human lung cancer cells. Cancer Biol Ther 13 727-736, 2012.

38. Liu PL, Tsai JR, Hwang JJ, Chou SH, Cheng YJ, Lin FY, Chen YL, Hung CY, Chen WC, Chen YH and Chong IW: High-mobility group box 1-mediated matrix metalloproteinase-9 expression in non-small cell lung cancer contributes to tumor cell invasiveness. Am J Respir Cell Mol Biol 43: 530-538, 2010.

39. Gribar SC, Richardson WM, Sodhi CP and Hackam DJ: No longer an innocent bystander: Epithelial toll-like receptor signaling in the development of mucosal inflammation. Mol Med 14: 645-659, 2008

40. Lotze MT, Zeh HJ, Rubartelli A, Sparvero LJ, Amoscato AA, Washburn NR, Devera ME, Liang X, Tör M and Billiar T: The grateful dead: Damage-associated molecular pattern molecules and reduction/oxidation regulate immunity. Immunol Rev 220: 60-81, 2007.

41. Kumagai Y, Takeuchi O and Akira S: Pathogen recognition by innate receptors. J Infect Chemother 14: 86-92, 2008.

42. Venereau E, De Leo F, Mezzapelle R, Careccia G, Musco G and Bianchi ME: HMGB1 as biomarker and drug target. Pharmacol Res 111: 534-544, 2016

43. Yanai H, Ban T, Wang Z, Choi MK, Kawamura T, Negishi H, Nakasato M, Lu Y, Hangai S, Koshiba R, et al: HMGB proteins function as universal sentinels for nucleic-acid-mediated innate immune responses. Nature 462: 99-103, 2009.

44. Beaulieu LM, Lin E, Morin KM, Tanriverdi K and Freedman JE: Regulatory effects of TLR2 on megakaryocytic cell function. Blood 117: 5963-5974, 2011.

45. Lin E, Freedman JE and Beaulieu LM: Innate immunity and toll-like receptor antagonists: A potential role in the treatment of cardiovascular diseases. Cardiovasc Ther 27: 117-123, 2009.

46. Dasu MR, Devaraj S, Park S and Jialal I: Increased toll-like receptor (TLR) activation and TLR ligands in recently diagnosed type 2 diabetic subjects. Diabetes Care 33: 861-868, 2010.

47. Kim J, Sohn E, Kim CS, Jo K and Kim JS: The role of high-mobility group box-1 protein in the development of diabetic nephropathy. Am J Nephrol 33: 524-529, 2011.

48. Singh B, Biswas I, Bhagat S, Surya Kumari S and Khan GA HMGB1 facilitates hypoxia-induced vWF upregulation through TLR2-MYD88-SP1 pathway. Eur J Immunol 46: 2388-2400, 2016.

49. Qiu Y, Yang J, Wang W, Zhao W, Peng F, Xiang Y, Chen G, Chen T, Chai C, Zheng S, et al: HMGB1-promoted and TLR2/4-dependent NK cell maturation and activation take part in rotavirus-induced murine biliary atresia. PLoS Pathog 10: e1004011, 2014.

50. Conti L, Lanzardo S, Arigoni M, Antonazzo R, Radaelli E, Cantarella D, Calogero RA and Cavallo F: The noninflammatory role of high mobility group box 1/Toll-like receptor 2 axis in the self-renewal of mammary cancer stem cells. FASEB J 27: 4731-4744, 2013

51. Zhang H, Yang N, Wang T, Dai B and Shang Y: Vitamin D reduces inflammatory response in asthmatic mice through HMGB1/TLR4/NF- $\kappa$ B signaling pathway. Mol Med Rep 17: 2915-2920, 2018

52. Gunasekaran MK, Virama-Latchoumy AL, Girard AC, Planesse C, Guérin-Dubourg A, Ottosson L, Andersson U, Césari M, Roche R and Hoareau L: TLR4-dependant pro-inflammatory effects of HMGB1 on human adipocyte. Adipocyte 5: 384-388, 2016

53. Yu LX, Yan L, Yang W, Wu FQ, Ling Y, Chen SZ, Tang L, Tan YX, Cao D, Wu MC, et al: Platelets promote tumour metastasis via interaction between TLR4 and tumour cell-released high-mobility group box1 protein. Nat Commun 5: 5256, 2014.

54. Ivanov S, Dragoi AM, Wang X, Dallacosta C, Louten J, Musco G, Sitia G, Yap GS, Wan Y, Biron CA, et al: A novel role for HMGB1 in TLR9-mediated inflammatory responses to CpG-DNA. Blood 110: 1970-1981, 2007.
55. Hemmi H, Takeuchi O, Kawai T, Kaisho T, Sato S, Sanjo H, Matsumoto M, Hoshino K, Wagner H, Takeda K and Akira S: A Toll-like receptor recognizes bacterial DNA. Nature 408: 740-745, 2000

56. Su Z, Wang T, Zhu H, Zhang P, Han R, Liu Y, Ni P, Shen H, $\mathrm{Xu} \mathrm{W}$ and $\mathrm{Xu} \mathrm{H}$ : HMGB1 modulates Lewis cell autophagy and promotes cell survival via RAGE-HMGB1-Erk1/2 positive feedback during nutrient depletion. Immunobiology 220: 539-544, 2015.

57. Ahmad-Nejad P, Häcker H, Rutz M, Bauer S, Vabulas RM and Wagner H: Bacterial CpG-DNA and lipopolysaccharides activate Toll-like receptors at distinct cellular compartments. Eur J Immunol 32: 1958-1968, 2002.

58. Latz E, Schoenemeyer A, Visintin A, Fitzgerald KA, Monks BG, Knetter CF, Lien E, Nilsen NJ, Espevik T and Golenbock DT: TLR9 signals after translocating from the ER to CpG DNA in the lysosome. Nat Immunol 5: 190-198, 2004.

59. Hacker H, Vabulas RM, Takeuchi O, Hoshino K, Akira S and Wagner $\mathrm{H}$ : Immune cell activation by bacterial CpG-DNA through myeloid differentiation marker 88 and tumor necrosis factor receptor-associated factor (TRAF)6. J Exp Med 192: 595-600, 2000

60. Ren T, Wen ZK, Liu ZM, Liang YJ, Guo ZL and Xu L: Functional expression of TLR9 is associated to the metastatic potential of human lung cancer cell: Functional active role of TLR9 on tumor metastasis. Cancer Biol Ther 6: 1704-1709, 2007.

61. Sun KK, Ji C, Li X, Zhang L, Deng J, Zhong N and Wu XY: Overexpression of high mobility group protein $\mathrm{B} 1$ correlates with the proliferation and metastasis of lung adenocarcinoma cells. Mol Med Rep 7: 1678-1682, 2013.

62. Wei F, Yang F, Li J, Zheng Y, Yu W, Yang L and Ren X: Soluble Toll-like receptor 4 is a potential serum biomarker in non-small cell lung cancer. Oncotarget 7: 40106-40114, 2016.

63. Xia Q, Xu J, Chen H, Gao Y, Gong F, Hu L and Yang L: Association between an elevated level of HMGB1 and non-small-cell lung cancer: A meta-analysis and literature review. Onco Targets Ther 9: 3917-3923, 2016.

64. Jakubowska K, Naumnik W, Niklinska W and Chyczewska E: Clinical Significance of HMGB-1 and TGF- $\beta$ level in serum and BALF of advanced Non-small cell lung cancer. Adv Exp Med Biol 852: 49-58, 2015.

65. Tang D, Kang R, Livesey KM, Cheh CW, Farkas A, Loughran P, Hoppe G, Bianchi ME, Tracey KJ, Zeh HJ III and Lotze MT: Endogenous HMGB1 regulates autophagy. J Cell Biol 190: 881-892, 2010

66. Kang R, Zeh HJ, Lotze MT and Tang D: The Beclin 1 network regulates autophagy and apoptosis. Cell Death Differ 18: 571-580, 2011.

67. Kang R, Tang D, Livesey KM, Schapiro NE, Lotze MT and Zeh HJ III: The receptor for advanced glycation End-products (RAGE) protects pancreatic tumor cells against oxidative injury. Antioxid Redox Signal 15: 2175-2184, 2011.

68. Kang R, Tang D, Schapiro NE, Livesey KM, Farkas A, Loughran P, Bierhaus A, Lotze MT and Zeh HJ: The receptor for advanced glycation end products (RAGE) sustains autophagy and limits apoptosis, promoting pancreatic tumor cell survival. Cell Death Differ 17: 666-676, 2010.

69. Copetti T, Bertoli C, Dalla E, Demarchi F and Schneider C: p65/RelA modulates BECN1 transcription and autophagy. Mol Cell Biol 29: 2594-2608, 2009.

70. Livesey KM, Kang R, Vernon P, Buchser W, Loughran P, Watkins SC, Zhang L, Manfredi JJ, Zeh HJ III, Li L, et al: p53/HMGB1 complexes regulate autophagy and apoptosis. Cancer Res 72: 1996-2005, 2012.

71. Zhang X, Wang $\mathrm{H}$ and Wang J: Expression of HMGB1 and $\mathrm{NF}-\kappa \mathrm{B}$ p65 and its significance in non-small cell lung cancer. Contemp Oncol (Pozn) 17: 350-355, 2013.

72. Zhang C, Ge S, Hu C, Yang N and Zhang J: MiRNA-218, a new regulator of HMGB1, suppresses cell migration and invasion in non-small cell lung cancer. Acta Biochim Biophys Sin (Shanghai) 45: 1055-1061, 2013.

73. Yao S, Zhao T and Jin H: Expression of MicroRNA-325-3p and its potential functions by targeting HMGB1 in non-small cell lung cancer. Biomed Pharmacother 70: 72-79, 2015.

74. Xiao P and Liu WL: MiR-142-3p functions as a potential tumor suppressor directly targeting HMGB1 in non-small-cell lung carcinoma. Int J Clin Exp Pathol 8: 10800-10807, 2015.

75. Liu Y, Hu X, Xia D and Zhang S: MicroRNA-181b is downregulated in non-small cell lung cancer and inhibits cell motility by directly targeting HMGB1. Oncol Lett 12: 4181-4186, 2016. 
76. Zhu J, Luo J, Li Y, Jia M, Wang Y, Huang Y and Ke S: HMGB1 induces human non-small cell lung cancer cell motility by activating integrin $\alpha v \beta 3 / \mathrm{FAK}$ through TLR4/NF- $\kappa \mathrm{B}$ signaling pathway. Biochem Biophys Res Commun 480: 522-527, 2016.

77. Stordal B and Davey M: Understanding cisplatin resistance using cellular models. IUBMB Life 59: 696-699, 2007.

78. Yang Y and Xian L: The association between the ERCC1/2 polymorphisms and the clinical outcomes of the platinum-based chemotherapy in non-small cell lung cancer (NSCLC): A systematic review and meta-analysis. Tumour Biol 35: 2905-2921, 2014

79. Wang Y, Li XP, Yin JY, Zhang Y, He H, Qian CY, Chen J, Zheng Y, Smieszkol K, Fu YL, et al: Association of HMGB1 and HMGB2 genetic polymorphisms with lung cancer chemotherapy response. Clin Exp Pharmacol Physiol 41: 408-415, 2014.

80. Spira A and Ettinger DS: Multidisciplinary management of lung cancer. N Engl J Med 350: 379-392, 2004.

81. Kelland L: The resurgence of platinum-based cancer chemotherapy. Nat Rev Cancer 7: 573-584, 2007.

82. Pan B, Chen D, Huang J, Wang R, Feng B, Song H and Chen L: HMGB1-mediated autophagy promotes docetaxel resistance in human lung adenocarcinoma. Mol Cancer 13: 165, 2014.

83. Krynetskaia NF, Phadke MS, Jadhav SH and Krynetskiy EY: Chromatin-associated proteins HMGB1/2 and PDIA3 trigger cellular response to chemotherapy-induced DNA damage. Mol Cancer Ther 8: 864-872, 2009.
84. Aranda F, Bloy N, Galluzzi L, Kroemer G and Senovilla L: Vitamin B6 improves the immunogenicity of cisplatin-induced cell death. Oncoimmunology 3: e955685, 2014

85. Amann R and Peskar BA: Anti-inflammatory effects of aspirin and sodium salicylate. Eur J Pharmacol 447: 1-9, 2002.

86. Wang H, Zhu S, Zhou R, Li W and Sama AE: Therapeutic potential of HMGB1-targeting agents in sepsis. Expert Rev Mol Med 10: e32, 2008

87. Lim SC, Kim SM, Choi JE, Kim CH, Duong HQ, Han SI and Kang HS: Sodium salicylate switches glucose depletion-induced necrosis to autophagy and inhibits high mobility group box protein 1 release in A549 lung adenocarcinoma cells. Oncol Rep 19: 1165-1171, 2008.

88. Ulloa L, Ochani M, Yang H, Tanovic M, Halperin D, Yang R, Czura CJ, Fink MP and Tracey KJ: Ethyl pyruvate prevents lethality in mice with established lethal sepsis and systemic inflammation. Proc Natl Acad Sci USA 99: 12351-12356, 2002.

89. Zhou RR, Kuang XY, Huang Y, Li N, Zou MX, Tang DL and Fan XG: Potential role of High mobility group box 1 in hepatocellular carcinoma. Cell Adh Migr 8: 493-498, 2014.

90. Guo X, Guo R, Luo X and Zhou L: Ethyl pyruvate ameliorates experimental colitis in mice by inhibiting the HMGB1-Th17 and Th1/Tc1 responses. Int Immunopharmacol 29: 454-461, 2015. 